\title{
Chronic exposure to high fat diet exacerbates arsenic-induced lung damages in male mice: Possible role for oxidative stress
}

\author{
Ali Asghar Hemmati1, Soheila Alboghobeish2, Akram Ahangarpour ${ }^{3}$ \\ 1 Department of Pharmacology, School of Medicine, Ahvaz Jundishapur University of Medical Sciences, Ahvaz \\ 2 Department of Pharmacology, School of Medicine, Student Research Committee of Ahvaz Jundishapur \\ University of Medical Sciences, Ahvaz \\ 3 Health Research Institute, Diabetes Research Center, Department of Physiology, Ahvaz Jundishapur \\ University of Medical Sciences, Ahvaz, Iran
}

\begin{abstract}
Arsenic is a common environmental and occupational contaminant worldwide which can influence the development of respiratory diseases. In recent years, alteration in the lifestyle as well as food habits have led to increased consumption of food containing high levels of fat. The present study was designed to evaluate the effects of chronic exposure to a highfat diet (HFD) on arsenic-induced damages and oxidative stress in the lung tissue of mice. This is the first study to reveal the effect of diet-induced obesity on arsenic-induced lung damages. Seventy-two male Naval Medical Research Institute (NMRI) mice were divided into six groups and fed an HFD or standard diet (SD) while being exposed to 25 or $50 \mathrm{ppm}$ of arsenic through drinking water for 20 weeks. At the end of the experiment, the lung weight to body weight ratio; oxidative stress markers, nitrite level, and hydroxyproline content in the lung tissue; and lung histology were evaluated. The results demonstrated that arsenic exposure leads to a significant decrease in the glutathione level and catalase enzyme activity, and significantly increased reactive oxygen species, malondialdehyde, and nitrite level, but it did not affect the superoxide dismutase activity and hydroxyproline content in the lung tissue. Consequently, all the parameters studied aggravated when HFD was consumed along with arsenic. These findings were confirmed by histological examination. Our study showed that HFD increased arsenic-induced lung damages through oxidative stress in mice. These findings could be important for clinical research to protect against arsenic-induced respiratory toxicity in humans.
\end{abstract}

Corresponding author: Soheila Alboghobeish, Department of Pharmacology, School of Medicine, Student Research Committee of Ahvaz Jundishapur University of Medical Sciences, Ahvaz, Iran.

Tel. +989.163077349 - Fax: +98.613.3332036. E-mail: alboghobeish.s@ajums.ac.ir

Key words: Lung; arsenic; high fat diet; oxidative stress.

Received for publication: 18 December 2017

Accepted for publication: 4 March 2018

(C) Copyright A.A. Hemmati et al., 2018

Tipografia PI-ME Editrice, Italy

Monaldi Archives for Chest Disease 2018; 88:903

doi: 10.4081/monaldi.2018.903

This article is distributed under the terms of the Creative Commons Attribution Noncommercial License (by-nc 4.0) which permits any noncommercial use, distribution, and reproduction in any medium provided the original author(s) and source are credited.

\section{Introduction}

Arsenic (As) is a heavy metalloid found in water, soil, and air. Although contact to arsenic occurs through both environmental and industrial sources, the common source of exposure worldwide is through inhalation and drinking water [1]. Many studies have linked arsenic exposure with an increased risk of cancers [2] and non-malignant diseases [3]. Consumption of arsenic in drinking water has also been associated with respiratory diseases [4]. Epidemiological data have associated arsenic exposure through the use of drinking water to chronic cough, chronic bronchitis, bronchiectasis, and obstructive lung diseases [5].

Recent studies have shown that arsenic induces toxicity by producing reactive oxygen species (ROS), and the intracellular peroxide level is associated with arsenic-induced cellular apoptosis [6]. Human lung tissue may be affected by arsenic toxicity because of the high partial pressure of oxygen and dimethylarsine, a gas that is excreted via the lungs [7]. Although lung is one of the main targets that is affected by arsenic, little evidence has been presented for the production of ROS in arsenic-exposed lung cells.

Industrialization and financial progress of modern society have led to modifications in diets of the people. A number of studies have discovered that diet is an important factor in arsenic-induced toxicity. HFD improved arsenic-induced hepatofibrogenesis [8] and heightened the gathering of arsenic in the liver tissue [9]. Many studies have indicated the presence of an imbalance between the formation of ROS and antioxidant defense system in the presence of respiratory damage or obesity [10]. For example, in patients with asthma or obesity, elevation of oxidative stress and changes in antioxidant defenses have been reported [11]. Albuali established that the serum level of malondialdehyde (MDA), a biomarker of oxidative stress, is increased whereas the serum levels of glutathione (GSH), an antioxidant, is decreased in obese children compared with that in the normal control group [12].

Because there is no evidence to show the effects of chronic exposure to HFD on arsenic toxicity in the respiratory system, the present study was designed to determine the relationship between consumption of HFD and arsenic-induced lung damages in mice.

\section{Materials and Methods}

\section{Animals and treatment}

Seventy-two adult male Naval Medical Research Institute (NMRI) mice $(25-30 \mathrm{~g})$ were purchased from the animal facility of the Ahvaz Jundishapur University of Medical Sciences. The animal experiments 
were conducted in accordance with animal care guidelines with an ethics committee approval No. IR.AJUMS.REC.1395.405. The mice consumed standard diet (SD) or HFD and arsenic in water for 20 weeks. The levels of arsenic in HFD (58\% fat) and SD (16\% fat) were 5 and $7 \mathrm{ppb}$ which contain very low concentration of arsenic compared to the ordered concentration ( 25 and $50 \mathrm{ppm}$ ) in this study. All mice were divided into six groups $(\mathrm{n}=12)$ as follows: SD (control group), SD +As25ppm, SD +As50ppm, HFD (control group), HFD+As25ppm, and HFD+ As50ppm [13].

\section{Sample preparation and analytical procedures}

At the end of the 20 -week experimental period, the animals were sacrificed and the lung were removed, weighed, and stored frozen at $-70^{\circ} \mathrm{C}$ until analysis. For the estimation of arsenic, a mineral extract of these samples was prepared by wet ingestion in a mixture of nitric acid, sulfuric acid, and perchloric acid. For complete conversion of arsenic V into arsenic III, potassium iodide and hydrochloric acid were added to the mineral extracts and incubated for $1 \mathrm{~h}$. Arsenic in the mineral extracts was determined by a hydride generation atomic absorption spectrophotometer [14].

\section{Preparation of lung homogenates}

The lung tissue washed with ice-cold saline and a 10\%homogenate ( $0.03 \mathrm{M}$ sodium phosphate buffer, $\mathrm{pH}-7.4$ ) of it was prepared by using an Ultra-Turrax T25 homogenizer at a speed of $9500 \mathrm{rpm}$ [15]. The homogenized tissue preparation was used for biochemical analysis.

\section{Determination of ROS, GSH and MDA levels in lung tissue}

The level of ROS in lung tissue was measured by using 2, 7-dichlorofluorescindiacetate (DCFDA) that converted into highly fluorescent DCF by cellular peroxides. Fluorescence was calculated using a fluorimeter, at 488nm excitation and $525 \mathrm{~nm}$ emission wavelength [16]. GSH contents were measured according to Thomas and Skrinska method. The GSH reacts with DTNB and forms a yellow-colored complex with it. The absorbance was read at $412 \mathrm{~nm}$. The result was expressed as $\mu$ moles of $\mathrm{GSH} / \mathrm{mg}$ protein [17]. The extent of lipid peroxidation in terms of malondialdehyde formation was measured. Briefly homogenate lung sample containing $1 \mathrm{ml}$ was mixed with $1 \mathrm{ml}$ TCA (20\%), $2 \mathrm{ml}$ TBA (0.67\%) and heated for $1 \mathrm{~h}$ in boiling water bath. After cooling, mixture centrifuged and absorbance of the supernatant measured at $532 \mathrm{~nm}$ against suitable blank. The amount of TBARS was calculated by using a molar extinction coefficient of $\varepsilon=1.56 \times 105 / \mathrm{M} / \mathrm{cm}$ and expressed as mol/mg protein [18].

\section{Determination of catalase enzyme and superoxide dismutase (SOD) in lung tissue}

Catalase activity was assayed according to the method used by $\mathrm{L}$. Goth. $500 \mu \mathrm{l}$ of $0.05 \mathrm{mmol}$ Tris- $\mathrm{HCl}, 1 \mathrm{ml} \mathrm{H}_{2} \mathrm{O}_{2}$ and $50 \mu \mathrm{l}$ of sample were mixed and incubated for $10 \mathrm{~min}$, and then Reaction was stopped by adding $500 \mu$ l Ammonium molybdate solution 4\%. The absorbance was read at $410 \mathrm{~nm}$. The result was expressed as U/mg protein [19]. The activity of SOD was determined using a xanthine/xanthine oxidase system for production of superoxide radical and subsequent measurement of Cytochrome- $C$ as a scavenger of the radicals. Optical density was determined using a spectrometer (UV-1601, Shimadzu) at $550 \mathrm{~nm}$. One unit of enzyme activity was defined as the quantity of SOD required to inhibit the rate of reduction of Cytochrome- $C$ by $50 \%$. SOD activity is presented as units per milligram of protein $(\mathrm{U} / \mathrm{mg}$ protein) [19].

\section{Determination of nitrite and hydroxyproline level in lung tissue}

Nitrite was estimated using Greiss reagent which served as an indicator of nitric oxide production. An amount of $100 \mu \mathrm{L}$ Greiss reagent (1:1 solution of $1 \%$ sulphanilamide in $5 \%$ phosphoric acid and $0.1 \%$ napthaylamine diamine dihydrochloric acid in water) was added to 100 $\mu \mathrm{L}$ of supernatant and absorbance was measured at $542 \mathrm{~nm}$ [20]. Lung hydroxyproline can be used as an indicator of collagen deposition. Lung hydroxyproline was determined spectrophotometrically and the results were expressed as micrograms of hydroxyproline per lung [21].

\section{Histopathological studies}

The right lungs tissues of mice were excised, fixed in buffered $10 \%$ formalin solution for $24 \mathrm{~h}$ and embedded in paraffin wax, then sectioned and stained with Hematoxylin and Eosin stain for histological examination under light microscope.

\section{Results}

Effect of diet and arsenic exposure on the body weight, average of daily water and arsenic intake

As expected, the HFD control mice weighed more than the SD control group $(\mathrm{p}<0.001)$, but coadministration of HFD and both concentrations of arsenic resulted in a significant weight loss in comparison with that in the HFD control group $(\mathrm{p}<0.01)$. The results of daily water intake showed that HFD control mice drank less water compared with the SD control group $(\mathrm{p}<0.01)$. Furthermore, administration of both concentrations of arsenic in the SD and HFD groups decreased the water intake compared with that in their control groups $(\mathrm{p}<0.01)$. The results of daily arsenic exposure indicated a significant and dose-dependent increase in the arsenic intake in the SD and HFD groups $(p<0.05)$. Moreover, there was a significant difference between the SD groups and their counterparts in the HFD groups $(\mathrm{p}<0.05)$ (Table 1).

\section{Effects of diet and arsenic exposure on oxidative and nitrosative stress in lung tissue}

The results of the lipid peroxidation analysis revealed that the lung tissue MDA level was significantly different in the two control groups. Also, arsenic exposure at a concentration of 50ppm significantly increased the MDA level in the HFD- and SD-fed mice when compared with that in their respective controls $(\mathrm{p}<0.05$ and $\mathrm{p}<0.01)$.

The glutathione assessment results showed that both arsenic doses significantly decreased the GSH level in the SD and HFD groups $(\mathrm{p}<0.01)$ and $(\mathrm{p}<0.001)$, and further, there was a significant difference between the HFD groups and their counterparts in the SD groups $(\mathrm{p}<0.01)$. Also, $50 \mathrm{ppm}$ arsenic exposure in the HFD and SD groups induced a significant increase of ROS in the lung tissue $(p<0.001)$, but ROS formation was not statistically significantly different between the HFD and SD control groups. Also, the results showed that HFD induced a significant rise in the nitrite levels in the lung tissue $(\mathrm{p}<0.001)$. Exposure to $50 \mathrm{ppm}$ arsenic increased this variable in the SD- and HFDfed mice $(\mathrm{p}<0.05)$ (Table 2).

\section{Effects of HFD and arsenic on catalase and SOD activity in lung tissue}

The results showed that catalase enzyme activity significantly decreased in the HFD control group compared with that in the SD control group $(\mathrm{p}<0.001)$. Furthermore, arsenic exposure at both doses signifi- 
cantly decreased this antioxidant enzyme in the SD- and HFD-fed mice $(\mathrm{p}<0.001)$. Also, the SOD activity was not statistically significantly different between the HFD and SD control groups. Arsenic exposure at $50 \mathrm{ppm}$ significantly increased the SOD activity in the HFD- $(\mathrm{p}<0.05)$ but not SD-fed mice when compared with their respective controls (Table 2).

\section{Effect of diet and arsenic exposure on lung weight to body weight ratio and lung distribution of arsenic}

The average total lung to body weight ratio after 20 weeks training was significantly lower in the HFD control mice compared with that in the SD controls $(\mathrm{p}<0.05)$. Further, arsenic exposure increased the lung to body weight ratio in both SD and HFD mice at 25 and $50 \mathrm{ppm}$ $(\mathrm{p}<0.01)$. This ratio increased in the HFD+As50ppm compared with that in the SD+As50ppm group ( $\mathrm{p}<0.05)$ (Figure 1A). Exposure to arsenic at 25 and 50ppm resulted in the accumulation of arsenic in the lungs of SD- and HFD-fed mice $(\mathrm{p}<0.001)$. Also, there was a significant difference between the HFD groups and their counterparts in the SD groups $(\mathrm{p}<0.05)$ (Figure 1B).

\section{Effects of arsenic and diet on hydroxyproline content in lung tissue}

As shown in figure1.C, exposure to a combination of HFD and 50 ppm arsenic significantly increased the content of hydroxyproline compared with that in the control group. Also, the content of hydroxyproline increased in the HFD+As 50ppm compared with that in the SD+As 50ppm group $(\mathrm{p}<0.05)$.

\section{Histopathological analysis}

Figure 2 A-C shows the histopathological assessments of the lung tissue of the experimental animals. A normal architecture of the pul- monary tissue was observed in the HFD and SD control groups, but in the SD+As 50ppm group, pulmonary edema was observed. In the HFD+As 50ppm group, inflammation and alveolar wall degeneration were observed.

\section{Discussion}

The present study has shown that HFD noticeably aggravates arsenic-induced lung injury by the induction of oxidative stress and reduction of antioxidant enzymes. Lung is one of the main target tissues in arsenic toxicity because of the high partial pressure of oxygen and dimethylarsine, which are excreted via the lungs [7]. Epidemiological data have associated arsenic exposure through the use of drinking water to chronic cough, chronic bronchitis, bronchiectasis, and obstructive lung diseases [5]. In one study, arsenic-induced skin lesions were linked to increased risk of respiratory diseases [22]. Arsenic is the only lung carcinogen that is active by both inhalation and ingestion and may be unique in its ability to increase the risk of numerous lung diseases via ingestion rather than inhalation [23]. Arsenic decreases the body weight by interfering with several metabolic pathways [24]. In the present study, we found that the consumption of HFD for 5 months led to increased body weight, but when HFD was administered along with arsenic, body weight decreased. Also, when HFD was administered with arsenic, the lung weight to body weight ratio increased. Based on these results, we proposed that arsenic exposure led to hypertrophy of the lung tissue. In addition, arsenic decreased water intake, and the same effect was revealed in the HFD control group when compared with the SD control group. Even though the animals treated with $50 \mathrm{ppm}$ arsenic and HFD drank less water compared with the SD control group, the results showed that they received a significant amount of arsenic. It was shown that arsenic collected in many tissues and organs. Our results indicated that chronic exposure to arsenic increases its level in the lungs of mice, and HFD suppressed this effect. A number of studies

Table 1. Effect of diet and arsenic exposure on the average of daily water drink, arsenic and calorie intake, and body weight.

\begin{tabular}{|c|c|c|c|c|c|c|c|}
\hline \multirow{2}{*}{ Variables $\quad$ Groups } & & \multicolumn{3}{|c|}{ Standard diet } & \multicolumn{3}{|c|}{ High fat diet } \\
\hline & & Control & As 25ppm & As 50ppm & Control & As 25ppm & As 50ppm \\
\hline Body weight (g) & & $38.58 \pm 3.1$ & $36.40 \pm 5.1$ & $35.75 \pm 3.3$ & $46.33 \pm 8.6^{\mathrm{a}^{*}}$ & $35.16 \pm 3.5^{b^{*}}$ & $29.08 \pm 2.4 \mathrm{~b}^{*}$ \\
\hline Water drink (ml/day) & 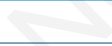 & $11.46 \pm 1.3$ & $7.52 \pm 0.7 \mathrm{a}^{*}$ & $4.56 \pm 1.5^{\mathrm{a}^{* *}}$ & $8.67 \pm 0.9 \mathrm{a}^{*}$ & $6.20 \pm 1.6^{b}$ & $4.29 \pm 1.4^{\mathrm{b}^{*}}$ \\
\hline Arsenic intake ( $\mu \mathrm{g} /$ day) & 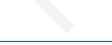 & 0 & $188.01 \pm 16.5$ & $228.31 \pm 24.9 c$ & 0 & $154.83 \pm 31.9 \mathrm{c}$ & $214.51 \pm 38.4 \mathrm{ed}$ \\
\hline
\end{tabular}

Each value was presented as means \pm SEM $(\mathrm{n}=12)$. aSignificantly different from control SD group $(\mathrm{p}<0.05)$; bsignificantly different from control HFD group $(\mathrm{p}<0.05) ;$; cignificantly different from $\mathrm{SD}+$ arsenic 25 ppm group; dsignificantly different from SD + As50 ppm group ( $\mathrm{p}<0.05)$; esignificantly different from HFD + arsenic $25 \mathrm{ppm}$ group $(\mathrm{p}<0.05) ; \mathrm{a}^{*}, \mathrm{~b}^{*}, \mathrm{e}^{*} \mathrm{p}<0.01 ; \mathrm{a}^{* *}, \mathrm{~b}^{* *} \mathrm{p}<0.001$. $\mathrm{p}$-values from one-way ANOVA, followed by Tukey's test for multiple comparisons.

Table 2. Effect of high fat diet and arsenic on antioxidant marker in lung tissue.

\begin{tabular}{lccccc}
\multicolumn{1}{c}{ Groups } & Standard diet & & High fat diet \\
Variables & Control & As 25ppm & As 50ppm & Control & As 25pm \\
As 50ppm
\end{tabular}

Data are meanSD; $n=12$. MDA, malondialdehyde; ROS, reactive oxygen species; GSH, glutathione. aSignificantly different from control SD ( $<<0.05$ ); bsignificant difference from control HFD ( $<0.05$ ); csignificant difference from SD + As 25 ppm ( $<<0.05)$; dsignificant difference from HFD + As 25 ppm ( $<<0.05)$; esignificant difference from SD + As 50 ppm ( $<<0.05) ; a^{*} b^{*} p<0.01, a^{* *}, b^{* *} p<0.001$. $p$-values from one-way ANOVA, followed by Tukey's test for multiple comparisons. 
have reported that consumption of HFD can produce cell membrane dysfunction by the induction of permeability and increase in lung inflammation [8]. So, according to the present results, it could be suggested that HFD can increase permeability and dysfunction of the cell membrane and cause more arsenic accumulation in the lung tissue.

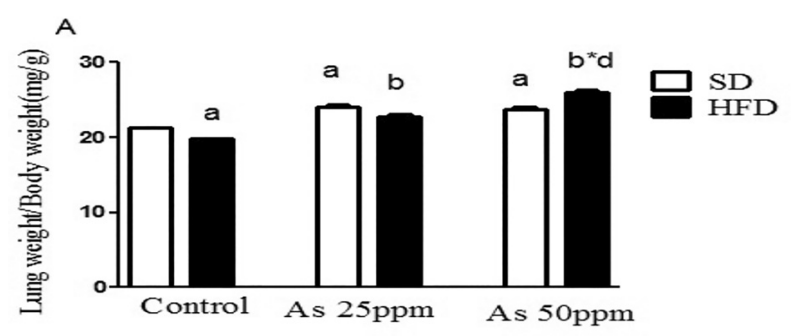

B

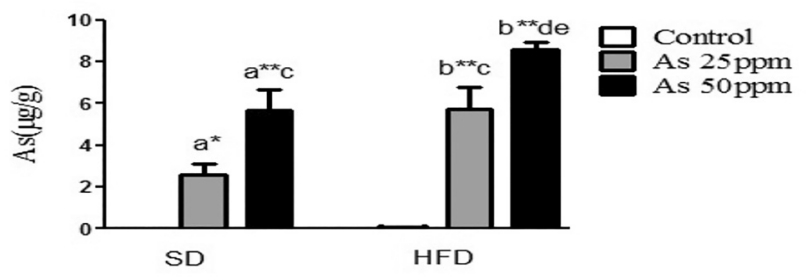$$
\text { c }
$$

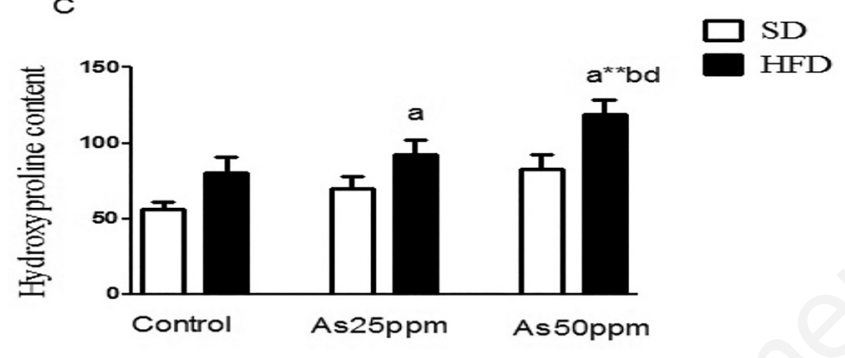

Figure 1. Effects of arsenic and diet on A) lung weight to body weight ratio; B) lung distribution of arsenic; C) lung hydroxyproline content (mean SE; $n=12$ ). a, significant difference from control SD $(\mathrm{p}<0.05) ; \mathrm{b}$, significant difference from control HFD $(\mathrm{p}<0.05)$; c, significant difference from SD + As $25 \mathrm{ppm}(\mathrm{p}<0.05)$; d, significant difference from HFD + As 25 ppm $(\mathrm{p}<0.05)$; e, significant difference from $S D+A s 50 \mathrm{ppm}(\mathrm{p}<0.05) ; \mathrm{a}^{*}, \mathrm{~b}^{*}, \mathrm{p}<0.01 ; \mathrm{a}^{* *}, \mathrm{~b}^{* *}$, $\mathrm{p}<0.001$. $\mathrm{p}$-values rom one-way ANOVA, followed by Tukey's test for multiple comparisons.
In this study, oxidative stress factors in the lung tissue have been evaluated. Previous studies have shown that oxidative stress plays a basic role in various types of respiratory diseases [25]. Also, many studies have shown that arsenic causes oxidative stress, oxidative damage, and decrease in the levels of antioxidants. 0xidative stress induced by arsenic may cause a change in the expression of antioxidant genes which contributes to the generation of free radicals such as ROS, activates the process of lipid peroxidation, elevates the level of tissue MDA, and decreases the GSH content [26]. Reduced glutathione can be the result of decreased synthesis or increased degradation/utilization of GSH by increased oxidative stress [27].

HFD increased the production of ROS as well as reduced the antioxidant defense mechanisms. Some studies have shown that on feeding an HFD, there are greater levels of oxidative stress biomarkers that are also associated with reduced antioxidant enzyme activities [28]. Evidence shows that an imbalance between the formation of ROS and antioxidant defense system is present in obesity [10].

The serum levels of MDA are significantly increased in obese children while the serum levels of glutathione are decreased [11]. Therefore, it seems that there is a relationship between obesity, respiratory diseases, and the elevation of oxidative stress. Hence, in agreement with the previous study, the findings from the present study indicate that arsenic in combination with HFD leads to an increase in the production of ROS and depletion of glutathione levels in the lung tissue.

The membrane polyunsaturated fatty acids are exceedingly susceptible to free radical-induced oxidative damage. The interaction between the free radicals and polyunsaturated fatty acids induces self-disseminating lipid peroxidation reactions which result in impaired membrane function and generation of MDA [29]. Our study also showed that arsenic exposure alone and in combination with HFD increases the lipid peroxidation in the lung tissue. Hence, a combination of both factors leads to excessive oxidative stress as a result of ROS production and lipid peroxidation of the membranes, thereby causing degradation of phospholipids, and finally, cellular deterioration in the lung tissue. The excessive oxidative stress could be due to the accumulation of free radicals as a result of increased lipid peroxidation due to HFD consumption and also free arsenic ions in the lung tissue.

Arsenic produces not only ROS but also hydrogen peroxide, hydroxyl radical species, dimethyl arsenic peroxyl radical, and dimethyl arsenic radical, which are known to be generated during arsenic toxicity [30]. In the present study, we showed that arsenic decreased the activity of the antiperoxidative enzyme, catalase, in the mice lung. This enzyme causes scavenging of hydrogen peroxides that are produced by arsenic
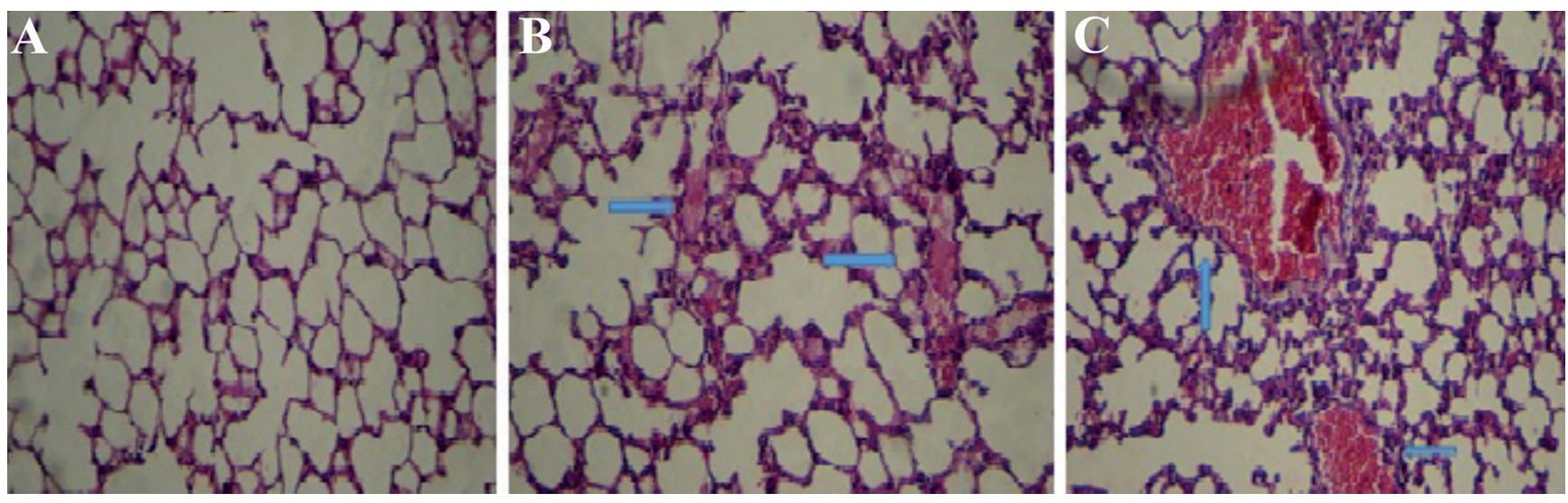

Figure 2. Effects of arsenic and diet on A) histopathological maps of lung, control groups; B) histopathological maps of lung, SD + arsenic $50 \mathrm{ppm}$; C) histopathological maps of lung, HFD + arsenic $50 \mathrm{ppm}$. H\&E (200x magnification). 
[31,32]. Thus, we suggest that arsenic could impair the ability to detoxify $\mathrm{H}_{2} \mathrm{O}_{2}$ via catalase resulting in the accumulation of $\mathrm{H}_{2} \mathrm{O}_{2}$ in the lung tissues.

Our results also indicated an increase in the nitrite level in the arsenic- and HFD-fed mice. The induction in nitrite level by arsenic and HFD may be due to its effect on the inducible nitric oxide synthase (iNOS) expression and upregulation of its expression in the lung tissue. Moreover, another study proposed that the source of airway oxidative stress in obesity is related to the generation of anion superoxide from airway iNOS [33].

Furthermore, in the current study, collagen deposition was determined by evaluating the total hydroxyproline content of the lung tissues. Our data found that arsenic and HFD increased the content of hydroxyproline in the lung tissue, and this rise was not significant, but exposure to a combination of HFD and $50 \mathrm{ppm}$ arsenic increased this variable significantly when compared with that in the control group. These results concur with that of a previous study that showed that treatment with arsenic elevated lung hydroxyproline content. These results indicated that the consumption of HFD along with arsenic-induced pulmonary inflammation and, probably, fibrosis in mice, but more studies are needed to prove it.

Lung injury that is induced by arsenic and HFD may affect the airways, lung parenchyma, mediastinum, pleura, pulmonary vasculature, and/or the neuromuscular system (34). Recognition of lung diseases is difficult because the clinical, radiological, and histological findings are nonspecific. The pulmonary tissues in the SD+As 50ppm group showed pulmonary edema. The alveolar wall capillaries seemed dilated, with slight inflammatory reaction, but showed little indication of degenerative modification. The HFD+As 50ppm group showed congestion, inflammation, and alveolar wall degeneration.

\section{Conclusions}

In conclusion, our study results reveal that chronic arsenic exposure through the drinking water produced lung injury, and HFD significantly enhanced it in mice. This effect may be explained by the reduced antioxidant activities and/or increased oxidative stress in the mice lung tissue. These findings could be important for a clinical intervention to protect against or prevent arsenic-induced respiratory damages in humans.

\section{References}

1. Lantz RC, Hays AM. Role of oxidative stress in arsenic-induced toxicity. Drug Metab Rev 2006;38:791-804.

2. Chiou H-Y, Hsueh Y-M, Liaw K-F, et al. Incidence of internal cancers and ingested inorganic arsenic: a seven-year follow-up study in Taiwan. Cancer Res 1995;55:1296-300.

3. Navas-Acien A, Silbergeld EK, Streeter RA, et al. Arsenic exposure and type 2 diabetes: a systematic review of the experimental and epidemiologic evidence. Environ Health Perspect 2006:641-8.

4. Ramsey KA, Larcombe AN, Sly PD, Zosky GR. In utero exposure to low dose arsenic via drinking water impairs early life lung mechanics in mice. BMC Pharmacol Toxicol 2013;14:13.

5. De B, Majumdar D, Sen S, et al. Pulmonary involvement in chronic arsenic poisoning from drinking contaminated ground-water. J Ass Physic India 2004;52:395-400.

6. Flora S, Bhadauria S, Kannan G, Singh N. Arsenic induced oxidative stress and the role of antioxidant supplementation during chelation: a review. J Environl Biol 2007;28:333.
7. K, Mizoi M, Kato K, et al. Oral administration of dimethylarsinic acid, a main metabolite of inorganic arsenic, in mice promotes skin tumorigenesis initiated by dimethylbenz (a) anthracene with or without ultraviolet B as a promoter. Biol Pharmaceut Bull 2001;24:510-4.

8. Wu J, Liu J, Waalkes MP, et al. High dietary fat exacerbates arsenicinduced liver fibrosis in mice. Exp Biol Med 2008;233:377-84.

9. Dutta M, Ghosh D, Ghosh AK, et al. High fat diet aggravates arsenic induced oxidative stress in rat heart and liver. Food Chem Toxicol 2014;66:262-77.

10. Mak JC, Ho SP, Ho AS, et al. Sustained elevation of systemic oxidative stress and inflammation in exacerbation and remission of asthma. ISRN Allergy 2013;2013-15.

11. Liu X, Lin R, Zhao B, et al. Correlation between oxidative stress and the NF- $\kappa \mathrm{B}$ signaling pathway in the pulmonary tissues of obese asthmatic mice. Mol Med Rep 2016;13:1127-34.

12. Albuali WH. Evaluation of oxidant-antioxidant status in overweight and morbidly obese Saudi children. World J Clin Pediatr 2014;3:6.

13. Paul DS, Walton FS, Saunders RJ, Stýblo M. Characterization of the impaired glucose homeostasis produced in C57BL/6 mice by chronic exposure to arsenic and high-fat diet. Environ Health Perspect 2011;119:1104.

14. Hershey J, Oostdyk T, Keliher P. Determination of arsenic and selenium in environmental and agricultural samples by hydride generation atomic absorption spectrometry. J Assoc Off Anal Chem 1988;71:1090.

15. Haring B, Van Delft W, Bom C. Determination of arsenic and antimony in water and soil by hydride generation and atomic absorption spectroscopy. Fresen Z Anal Chem 1982;310:217-23.

16. Sokolovic D, Djindjic B, Nikolic J, et al. Melatonin reduces oxidative stress induced by chronic exposure of microwave radiation from mobile phones in rat brain. J Radiat Res 2008;49:579-86.

17. Jain A, Yadav A, Bozhkov A, et al. Therapeutic efficacy of silymarin and naringenin in reducing arsenic-induced hepatic damage in young rats. Ecotoxicol Environ Saf 2011;74:607-14.

18. Draper H, Hadley M. Malondialdehyde determination as index of lipid peroxidation. Methods Enzymol 1990;186:421-31.

19. Kakkar P, Das B, Viswanathan P. A modified spectrophotometric assay of superoxide dismutase. Indian $\mathrm{J}$ Biochem Biophy. 11984;34-42

20. Green LC, Wagner DA, Glogowski J, et al. Analysis of nitrate, nitrite, and nitrate in biological fluids. Anal Biochem 1982;126:131-8.

21. Zhu T, Zhang W, Xiao M, Chen H, Jin H, et al. Protective role of andrographolide in bleomycin-induced pulmonary fibrosis in mice. Int J Mol Scis 2013;14:23581-96.

22. Ghosh P, Banerjee M, De Chaudhuri S, et al. Comparison of health effects between individuals with and without skin lesions in the population exposed to arsenic through drinking water in West Bengal, India. J Expo Sci Environ Epidemiol 2007;17:215-23.

23. Kozul CD, Hampton TH, Davey JC, et al. Chronic exposure to arsenic in the drinking water alters the expression of immune response genes in mouse lung. Environ Health Perspect 2009;117:1108-14.

24. Sedeek M, Nasrallah R, Touyz RM, Hébert RL. NADPH oxidases, reactive oxygen species, and the kidney: friend and foe. J Am Soc Nephrol 2013;24:1512-8.

25. Alfadda AA, Sallam RM. Reactive oxygen species in health and disease. BioMed Res Int 2012:2012-20.

26. Rossman TG. Molecular and genetic toxicology of arsenic. Environ Toxicol 1998;17:17-22.

27. Chen YC, Lin-Shiau SY, Lin JK. Involvement of reactive oxygen species and caspase 3 activation in arsenite-induced apoptosis. J Cell Physiol 1998;177:324-33. 
28. Noeman SA, Hamooda HE, Baalash AA. Biochemical study of oxidative stress markers in the liver, kidney and heart of high fat diet induced obesity in rats. Diabetol Metab Syndr 2011;3:17-23.

29. Lynn S, Gurr J-R, Lai H-T, Jan K-Y. NADH oxidase activation is involved in arsenite-induced oxidative DNA damage in human vascular smooth muscle cells. Circ Res 2000;86:514-9.

30. Webb D, Wilson S, Carter D. Comparative pulmonary toxicity of gallium arsenide, gallium (III) oxide, or arsenic (III) oxide intratracheally instilled into rats. Toxicol Appl Pharmacol 1986;82:405-16.

31. Kirkman HN, Gaetani GF. Catalase: a tetrameric enzyme with four tightly bound molecules of NADPH. Proc Natl Acad Sci USA 1984;81:4343-7.

32. Grasemann C, Herrmann R, Starschinova J, et al. Effects of fetal exposure to high-fat diet or maternal hyperglycemia on L-arginine and nitric oxide metabolism in lung. Nutr Diabetes 2017;7:e244.

33. Singh VP, Aggarwal R, Singh S, et al. Metabolic syndrome is associated with increased oxo-nitrative stress and asthma-like changes in lungs. PloS One 2015;10:e0129850.

34. Beasley MB. The pathologist's approach to acute lung injury. Arch Pathol Lab Med 2010;134:719-27. 